\title{
Effect of hyperbaric oxygenation on the expression of glutathione peroxidase 4 and lactoperoxidase genes in the lung of isogenic mice after ischemia/reperfusion injury in the small bowel ${ }^{1}$
}

Adauto Tsutomu Ikejiri', Frederico Somaio Neto", Paulo Roberto Bertoletto", José Carlos Chaves"I, Alexandre Key WakateTeruyalv, Cândida Aparecida Leite Kassuyav, Murched Omar Tahavi, Djalma José Fagundes ${ }^{\mathrm{VII}}$

'PhD, Assistant Professor, Medical School, Universidade Federal da Grande Dourados (UFGD), Brazil. Acquisition, analysis and interpretation of data; technical procedures; statistical analysis; manuscript preparation and writing.

"PhD, Associate Professor, Medical School, UFGD, Dourados-MS, Brazil. Acquisition, analysis and interpretation of data; technical procedures.

"IPhD, Assistant Professor, Medical School, UFGD, Dourados-MS, Brazil. Acquisition, analysis and interpretation of data; technical procedures.

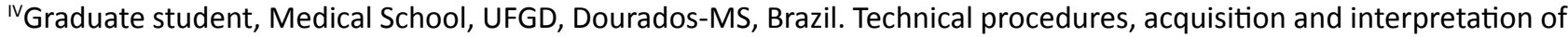
data.

${ }^{\vee}$ PhD, Associate Professor, Medical School, UFGD, Dourados-MS, Brazil. Analysis and interpretation of data, statistical analysis, critical revision.

VIPhD, Associate Professor, Division of Surgical Techniques and Experimental Surgery, Department of Surgery, Universidade Federal de São Paulo (UNIFESP), Brazil. Conception and design of the study, critical revision.

VIIPhD, Full Professor, Division of Surgical Techniques and Experimental Surgery, Department of Surgery, UNIFESP, Sao Paulo-SP, Brazil. Conception and design of the study, critical revision, final approval.

\section{Abstract}

Purpose: To evaluate the effect of hyperbaric oxygenation (HBO) on the expression of the genes antioxidant glutathione peroxidase $4(\mathrm{Gpx} 4)$ and lactoperoxidase (Lpo) in the lung of mice subjected to intestinal ischemia and reperfusion (IIR).

Methods: Control group (CG) in which were subjected to anesthesia, laparotomy and observation for 120 minutes; an ischemia and reperfusion group (IRG) subjected to anesthesia, laparotomy, small bowel ischemia for 60 minutes and reperfusion for 60 minutes; and three groups treated with HBO during ischemia $(H B O G+1)$, during reperfusion $(H B O G+R)$ and during ischemia and reperfusion $(H B O G+I R)$. Studied 84 genes of oxidative stress by the method (RT-qPCR). Genes with expression levels three times below or above the threshold cycle were considered significantly hypoexpressed or hyperexpressed, respectively (Student's t-test $p<0.05$ ).

Results: Gpx4 and Lpo were hiperexpressed on IRG, showing a correlation with these genes with lung oxidative stress. Treated with $\mathrm{HBO}$, there was a significant reduction on genic expression on $\mathrm{HBOG}+\mathrm{l}$. Conclusion: Hyperbaric oxygenation showed to be associated with decreased expression of these antioxidant genes, suggesting a beneficial effect on the mechanism of pulmonary oxidative stress whenever applied during the ischemia.

Key words: Hyperbaric Oxygenation. Gene Expression. Glutathione Peroxidase. Lactoperoxidase. Reperfusion Injury. Mice. 


\section{Introduction}

The phenomenon of intestinal ischemia and reperfusion (IIR) frequently occurs in connection with abdominal organ transplants, arterial and venous occlusive diseases of the digestive tract and circulatory shock ${ }^{1}$. IIR is usually associated with the development of inflammation, microcirculatory dysfunction, and the production of reactive oxygen species (ROS) that damage local tissue as well as tissue in distant organs. Reports show that individuals who experience IIR are at risk of developing lung damage via the action of $\operatorname{ROS}^{2,3}$.

The triggering factor of the abovedescribed process is oxygen $\left(\mathrm{O}_{2}\right)$ deficiency; therefore, supply of $\mathrm{O}_{2}$ under hyperbaric conditions has emerged as a new option for avoiding the sequence of deleterious events associated with IIR.

The supply of an oxygen-rich environment (100\% medical oxygen) under atmospheric pressure of two to three atmosphere absolute (ATA) favors the diffusion of $\mathrm{O}_{2}$ into plasma and bodily fluids. Under these conditions, hyperbaric oxygenation (HBO), by providing an increased concentration of $\mathrm{O}_{2}$ in bodily fluids, can decrease or even prevent the formation of ROS, even during circulatory compromise $^{4,5}$. Thus, HBO may act by protecting tissues against the harmful effects of free radicals and disrupting the activation of pulmonary oxidative stress signaling pathways.

Due to their high sensitivity, specificity and reproducibility, genomic approaches using molecular biology techniques permit the reliable evaluation of the expression levels of a large number of genes. This is relatively simplified by the use of reverse transcription and quantitative polymerase chain reaction (RT-qPCR) in real time ${ }^{6-8}$. This technique permits study of the expression of genes involved in oxidative stress and antioxidant defense both in local organs ${ }^{8}$ and in organs distant from ischemia ${ }^{9,10}$, allowing a better understanding of the various aspects of this phenomenon in the diagnosis, monitoring and treatment of ischemic disease.

Assuming that gene expression is quantitatively related to the need for proteins encoded by specific genes, the aim of this study was to investigate the expression of genes associated with oxidative stress and antioxidant defense in the lung tissue of isogenic mice after IIR and to concomitantly evaluate the effects of $\mathrm{HBO}$ on the expression of these genes.

\section{Methods}

The study was approved by the Ethics Committee on Animal Use (ECAU) of the Universidade Federal de São Paulo (UNIFESP) under number 7101170714 and ratified by the ECAU of Universidade Federal da Grande Dourados (UFGD) under number 19/2015.

Thirty male adult mice (C57/BL6 lineage, mean weight 30 grams) were obtained from the Center for the Development of Experimental Models for Medicine and Biology (Centro de Desenvolvimento de Modelos Experimentais para Medicina e Biologia CEDEME) of UNIFESP and housed in cages appropriate for the species under conditions of controlled temperature and humidity, a 12-hour light/dark cycle and air exhaust. The animals had free access to water and pelleted feed until 6 hours prior to the surgical procedures. All surgical and HBO procedures were performed at the Laboratory of Experimental Surgery, Department of Surgery, School of Health Sciences, UFGD.

Anesthesia, surgery and material collection

The animals were anesthetized by intramuscular injection of ketamine hydrochloride $\left(44 \quad \mathrm{mg} . \mathrm{kg}^{-1}\right), \quad$ xylazine 
hydrochloride $\left(2.5 \mathrm{mg} . \mathrm{kg}^{-1}\right)$, and acepromazine (0.75 mg.kg-1) at a dose of $0.02 \mathrm{~mL} 30 \mathrm{~g}^{-1}$. The animals were randomly divided into five groups of six animals each. The Control Group (CG) was subjected to anesthesia and median laparotomy without occlusion of the superior mesenteric vessels and was observed for 120 minutes. The Ischemia Reperfusion Group (IRG) was subjected to 60 minutes of ischemia and 60 minutes of reperfusion without the application of $\mathrm{HBO}$. The other three groups were treated with $\mathrm{HBO}$ during different periods: during ischemia $(\mathrm{HBOG}+\mathrm{I})$, during reperfusion ( $H B O G+R$ ) and during ischemia and reperfusion (HBOG $+\mathrm{IR}$ ).

Samples of tissue were collected from the small intestine and lung. The lung and intestinal segment fragments were washed with saline, wrapped in aluminum foil, labeled, immersed in liquid nitrogen $\left(-196^{\circ} \mathrm{C}\right)$ and sent to the Laboratory of Molecular Biology, Department of Gynecology, UNIFESP, for gene expression processing.

\section{Hyperbaric chamber}

The small-animal hyperbaric chamber consisted of a basic carbon steel cylindrical structure with an internal diameter of 50 $\mathrm{cm}$ and a hermetic front cover fastened by screws. The chamber was designed for use with a maximum resistance of $400 \mathrm{kPa}$ or 4 bar and a maximum working temperature of $50^{\circ} \mathrm{C}$.

\section{HBO procedure}

The HBO procedure consisted of maintaining pressure at 3.0 ATA and $100 \%$ oxygen. The animals in the HBOG + I group were placed in the chamber for 60 minutes immediately after the application of the clamp; they were then removed from the chamber, the vascular clamp was removed, and reperfusion was conducted for 60 minutes at normal atmospheric pressure. The animals in the $\mathrm{HBOG}+\mathrm{R}$ group received $\mathrm{HBO}$ during reperfusion, and those in the HBOG + IR group received $\mathrm{HBO}$ during the entire period of ischemia and reperfusion.

\section{Procedures for the determination of gene expression}

The $\mathrm{RT}^{2}$ Profiler ${ }^{\mathrm{TM}} \mathrm{PCR}$ array (SA Biosciences, Frederick, MD, USA; cat \# PAMM 065) was used to evaluate the expression of 84 genes related to the effects of oxidative stress and antioxidant defense. RNA was extracted from the samples using TRIzol reagent (Life Technologies, Grand Island, NY, USA) and purified by reverse adsorption (RNeasy Mini Kit, Qiagen Co., USA). The RNA concentration was determined using a spectrophotometer, and the quality of the results was measured by analysis of the RNA by electrophoresis in $2 \%$ agarose gels. The first complementary DNA (cDNA) strand was synthesized using $1 \mu \mathrm{g}$ of total RNA and the First Chain RT2 kit (SABiosciences). Identical amounts of cDNA and Master Mix SYBR ${ }^{\circ}$ Green qPCR Master Mix (SABiosciences) were distributed into 96 wells of a PCR array containing specific genes. Quantitative PCR was performed according to the manufacturer's instructions. Five endogenous control genes (ACTB, Gapdh, Hsp90ab1, Hprt1, and Gusb) were used in the PCR array, and a negative contamination control was employed. PCR positive controls (PPCs) were used to determine the efficiency of the polymerase chain reaction. These controls use a predefined DNA sequence in the detection process. The replication control wells (RTCS and PPCs) also evaluate the consistency between the wells and among the plates. The software provided with the device (MxPro 
Equipment Real Time Systems, Stratagene, GE Co.) was used to calculate the start cycle values $(\mathrm{Ct})$. Finally, a pairwise comparison was performed by calculating changes in gene expression from the pure initial cycle using the $\left(2^{-\Delta \Delta c t}\right)$ method.

The results of the method used to determine the relative expression of the genes of interest in this study were placed in the data analysis table of PCR Array v3.3 (PCR Array Data Analysis v3.3, SABiosciences).

\section{Statistical analysis}

For the gene expression data, the software calculated the variation in the quantification cycle $(\mathrm{Ct})$ of the studied groups (IRG, HBOG + I, HBOG + R and HBOG + IR) compared to the quantification cycle $(\mathrm{Ct})$ of the control group expressed in base-2 logarithmic form using the formula $\left(2^{-\Delta \Delta c t}\right)$. Values that exceeded three times the expression threshold were considered relevant and were classified as indicating hyper- or hypoexpression. The samples were evaluated in triplicate. Student's t-test $(p<0.05)$ was used to validate the homogeneity of the reaction. Statistically significant differences are indicated by asterisks $\left({ }^{*}\right)$.

\section{Results}

Figure 1 shows the expression profiles of 84 genes related to oxidative stress and antioxidant defense in intestinal and pulmonary tissue during IIR according to the criteria of positive $(+)$ (above the threshold) expression, negative (-) (below the threshold) expression, hyperexpression (three times above the threshold), and hypoexpression (three times below the threshold).

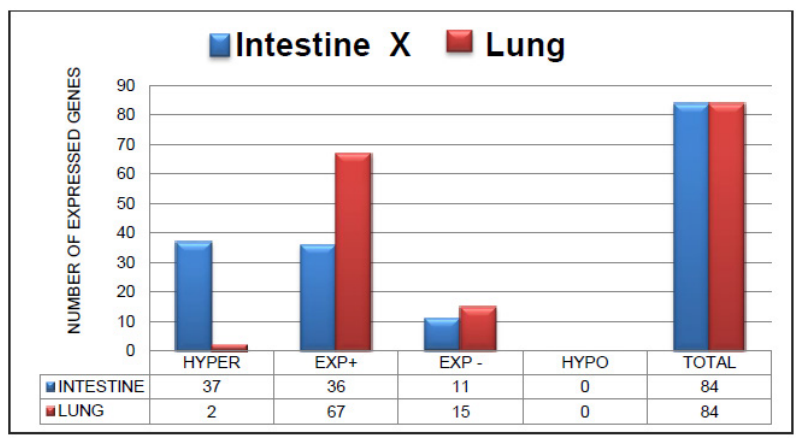

Figure 1 - Expression of the 84 genes in the intestine and lung of the animals subjected to intestinal ischemia and reperfusion (IRG) according to the criteria of positive $(+)$ expression, negative (-) expression, hyperexpression (three times above the threshold) and hypoexpression (three times below the threshold).

In the intestinal tissue of the group that was subjected to intestinal ischemia and reperfusion (IRG), $73(86.90 \%)$ of the 84 (100\%) genes presented positive expression. Of these 73 genes, 37 (44.04\%) were hyperexpressed, and 36 (42.86\%) showed positive expression. Eleven genes (13.09\%) showed negative expression. No gene presented hypoexpression.

In the lung tissue of the IRG, 69 genes with positive expression (82.14\%) were found. Of these 69 genes, 67 (79.76\%) showed positive expression, and $2(2.38 \%)$ showed hyperexpression. Fifteen genes (17.86\%) displayed negative expression, and no hypoexpressed genes were found.

\section{Relevant gene expression results}

Table 1 presents the data on the expression of the genes encoding glutathione peroxidase $4(G p \times 4)$ and lactoperoxidase ( $L p o)$ in the lung; among the 84 genes associated with oxidative stress and antioxidant defense, these showed hyperexpression during IIR and were thus considered relevant. 
Figure 2 and Table 1 show the expression of the gene encoding Gpx4 in the animals subjected to IIR; this gene showed hyperexpression in the IRG. Treatment with HBO significantly reduced the expression of this gene in the HBOG + I and HBOG + R groups.

Table 1 - Expression of genes encoding glutathione peroxidase 4 and lactoperoxidase in the lung. Genes showing hyperexpression ( + and in bold) in the IRG and positive expression (+) or negative expression (-) in the other three groups under the effect of $\mathrm{HBO}$ (during ischemia (HBOG $+\mathrm{I}$ ), during reperfusion ( $H B O G+R)$ and during ischemia and reperfusion $(H B O G+I R)$ ) are indicated. Significant values are marked with asterisks $\left(^{*}\right)$ (Student's t-test, $\left.\mathrm{p}<0.05\right)$.

\begin{tabular}{llllllll}
\hline$\#$ & $\begin{array}{c}\text { Gene } \\
\text { bank }\end{array}$ & $\begin{array}{c}\text { Gene } \\
\text { symbol }\end{array}$ & \multicolumn{1}{c}{$\begin{array}{c}\text { Gene } \\
\text { description }\end{array}$} & GIRG & HHBOG + I & $\begin{array}{c}\text { HHBOG } \\
+\mathbf{R}\end{array}$ & $\begin{array}{c}\text { HBOG } \\
+ \text { IR }\end{array}$ \\
\hline $\mathbf{1}$ & NM_008162 & GGpx4 & Glutathione peroxidase 4 & $\mathbf{+ 4 . 1 0 ^ { * }}$ & $++2.13^{*}$ & $++2.19^{*}$ & ++1.38 \\
$\mathbf{2}$ & NM_080420 & LLpo & Lactoperoxidase & $\mathbf{+ + 3 . 5 1 *}$ & $--1.30^{*}$ & -1.11 & ++1.71 \\
\hline
\end{tabular}

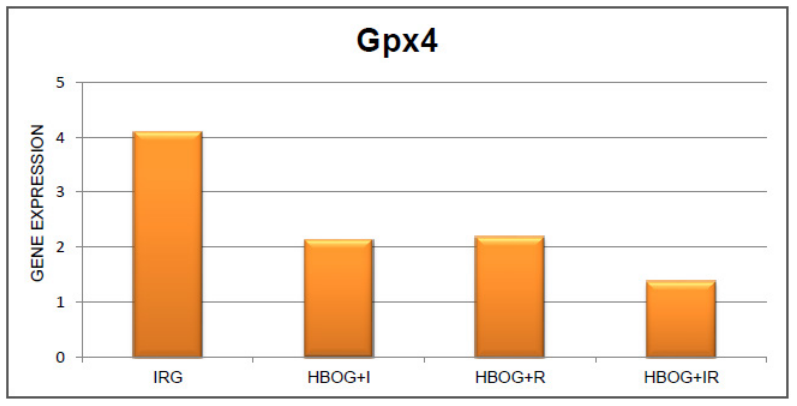

Figure 2 - Expression of the gene encoding glutathione peroxidase 4 in the lung tissue of animals subjected to intestinal ischemia and reperfusion (IRG) and in the lung tissue of animals treated with HBO during ischemia $(\mathrm{HBOG}+\mathrm{I})$, during reperfusion ( $H B O G+R)$, and during ischemia and reperfusion ( $H B O G+I R)$.

Figure 3 and Table 1 show the expression of the gene encoding $L p o$ in the animals subjected to IIR; this gene showed hyperexpression in the IRG. Treatment with HBO significantly reduced the expression of this gene in the $\mathrm{HBO}+$ I group.

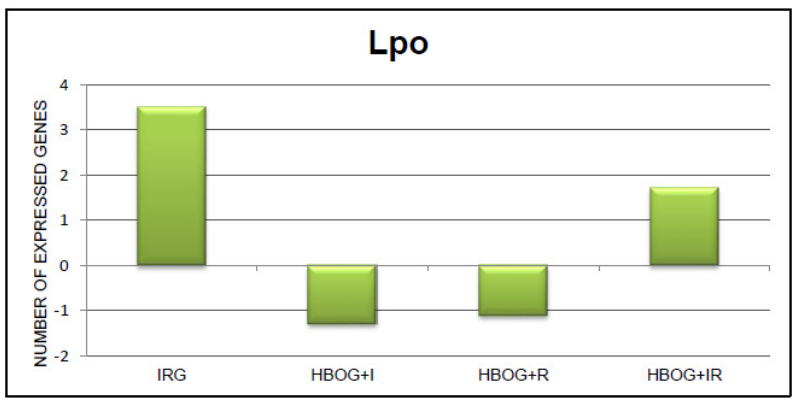

Figure 3 - Expression of the gene encoding lactoperoxidase in the lung tissue of animals subjected to intestinal ischemia and reperfusion (IRG) and in the lung tissue of animals treated with $\mathrm{HBO}$ during ischemia $(\mathrm{HBOG}+\mathrm{I})$, during reperfusion $(H B O G+R)$ and during ischemia and reperfusion $(H B O G+I R)$.

\section{Discussion}

In the analysis of the expression of 84 genes related to oxidative stress and antioxidant response in intestinal and pulmonary tissue (Figure 1), it was observed that most of the genes presented positive expression, a small portion manifested negative expression and no gene presented hypoexpression. The absolute numbers representing the changes 
in gene expression in the two tissues are quite similar, which suggests that the two tissues may have similar metabolic response pathways associated with oxidative stress. It was also considered that therapeutic measures such as $\mathrm{HBO}$ that benefit one tissue may be favorable to other tissues.

We found that 37 genes in the intestine and 2 genes in the lung were hyperexpressed. These numbers, which are quite different, seem reasonable because ischemia and reperfusion injury in the bowel is expected to be much more severe in local $^{8}$ tissue than in distant tissues ${ }^{9-11}$. Moreover, in the lung tissue a peculiarity occurs: oxygen reaches the alveoli by two routes, perfusion and ventilation. This alveolar oxygen helps maintain aerobic metabolism and delays the occurrence of hypoxia ${ }^{12}$. This mechanism would tend to protect lung tissue from oxidative stress and delay the onset of damage, resulting in less need to produce antioxidant proteins compared to other tissue such as the intestine.

Sixty-seven genes (Figure 1) were positively expressed, indicating that the lung responds with a positive expression profile during IIR. This means that in the IRG, there was a stimulus for greater production of proteins related to oxidative stress and antioxidant defense. Thus, two genes that showed hyperexpression, Gpx4 and Lpo, were identified. These two genes were chosen for analysis to determine the similarities or differences in metabolic responses to oxidative stress and to evaluate the effects of HBO in the different groups.

\section{Glutathione peroxidase 4}

The Gpx4 gene encodes a protein that belongs to a family of glutathione peroxidaserelated enzymes. Glutathione in tissues is found almost exclusively in its reduced form; this form is produced by glutathione reductase, which is chemically activated by oxidative stress, i.e., by an imbalance between ROS and intrinsic cellular defenses and humoral antioxidants ${ }^{13,14}$. One of the important biological functions of glutathione peroxidases is protection of the body against the deleterious effects of oxidative stress by catalyzing the reduction of $\mathrm{H}_{2} \mathrm{O}_{2}$ and organic hydroperoxides; in this way, it plays an active role in the removal of ROS inside cells ${ }^{13,14}$. Reduced glutathione is found in high concentrations in bronchial and alveolar lavage, and it confers protection to the lung against oxidative damage. This protective effect has been confirmed in studies in which glutathione depletion has been linked to increased risk of lung disease ${ }^{15}$. GPX4 is a key enzyme in the protection against lipid peroxidation. It differs from other glutathione peroxidases in that only GPX4 can reduce the hydroperoxides found in lipoproteins and complex lipids such as those derived from cholesterol, cholesterol esters and phospholipids ${ }^{16,17}$. Because of this, it is believed that GPX4 plays a key role in protecting biomembranes against oxidative damage.

The hyperexpression of the Gpx4 gene found in this study suggests that the genetic apparatus that controls the expression of this gene responsible for antioxidant defense in lung tissue responded significantly to the aggressor stimulus provoked by the oxidative stress at a distance due to IIR. HBO treatment of animals subjected to ischemia and reperfusion triggered a decrease in this response. It can thus be inferred that treatment with HBO resulted in a lower gene response, suggesting that the effect was beneficial to lung tissue by reducing the oxidative stress due to IIR.

\section{Lactoperoxidase}

The Lpo gene also displayed great sensitivity to pulmonary oxidative stress triggered by IIR. The ideal substrate for this enzyme is hydrogen peroxide, but other compounds such as organic hydroperoxides 
(lipid peroxides) are more active substrates. LPO is an oxidoreductase that is found in various mucous glands such as salivary and mammary glands, and it plays an important role as a natural antimicrobial agent ${ }^{18,19}$. In the lung, LPO is found in the submucosal glands of the trachea and bronchi and is transported into the lumen of the airway, where it exerts its enzymatic activity ${ }^{20}$. Although the enzymatic system of lactoperoxidase does not attack DNA, under certain circumstances it may contribute to oxidative stress ${ }^{21}$.

Hydrogen peroxide $\left(\mathrm{H}_{2} \mathrm{O}_{2}\right)$, a ROS and an inflammatory mediator, is known to play an important role in airway homeostasis. For this reason, control of its levels and thus its synthesis and consumption is an important mechanism in the control of airway functions. LPO was identified as its main consumer. This enzyme uses $\mathrm{H}_{2} \mathrm{O}_{2}$ to oxidize the thiocyanate anion into an antibiotic compound that prevents the growth of bacteria, fungi and viruses. The role of this enzyme in the defense of host airways strongly suggests that an active system of $\mathrm{H}_{2} \mathrm{O}_{2}$ production exists to provide the appropriate substrate for the enzyme. The identity of this $\mathrm{H}_{2} \mathrm{O}_{2}$ synthesis system is an important yet unknown feature of the metabolism of this ROS in the airways ${ }^{22,23}$.

The expression of LPO can be controlled by at least two different regulatory mechanisms. In the first of these mechanisms, LPO is regulated by stimuli such as bacterial adherence or bacterial products ${ }^{24}$, whereas in the second mechanism, airway peroxidase is controlled by the stimulation of $\beta$-adrenergic receptors ${ }^{25}$.

In our study, the expression of the $L p o$ gene in lung tissue was modified by the action of HBO. This suggests that LPO protein levels can also be regulated by the effect of $\mathrm{HBO}$ and indicates the existence of a third regulatory mechanism of LPO expression. The finding of Lpo hyperexpression in the current model may be associated with the presence of excessive amounts of ROS, especially $\mathrm{H}_{2} \mathrm{O}_{2}$ and organic hydroperoxides, resulting from oxidative stress to the lung tissue due to IIR injury, and it suggests a possible protective action of $L p o$ against the deleterious effects of ROS. In animals treated with $\mathrm{HBO}$ during ischemia, a decrease in the expression of the Lpo gene was observed; thus, it could be inferred that the beneficial action of HBO led to lower production of ROS and a consequent reduction in oxidative stress.

HBO is a well-established treatment modality for several diseases ${ }^{4,5}$. However, there are still questions about its effects and how they depend on session duration and interval, the technical details of the types of equipment used, and its therapeutic efficacy in some diseases ${ }^{26-28}$.

The mechanism of action of $\mathrm{HBO}$ is based on an increase in the pressure of the gases in the environment, which is described by Boyle's and Henry's laws. The higher the pressure on a liquid, the greater the amount of gas that can be dissolved in this liquid; the increase in oxygen partial pressure facilitates the diffusion of oxygen into the tissues even without perfusion by the blood vessels ${ }^{28}$.

The actions attributed to HBO include the molecular action of inducing an early event associated with post-ischemic tissue reperfusion, which is the inhibition of the adhesion of circulating neutrophils to the vascular endothelium mediated by $\beta 2$ integrin ${ }^{29}$. HBO does not reduce the viability or the function of neutrophils; the degranulation, phagocytosis and chemotaxis of neutrophils remain intact.

The induction of an anti-inflammatory pathway by HBO involves a decrease in the production of proinflammatory cytokines by monocytes and macrophages ${ }^{30}$. The molecular mechanism of this effect is unknown, but the cells exhibit decreased production of IL1, IL- 6 and TNF- $\alpha$ due to decreased stimulus 
after HBO. Physiologically, this suppression of inflammatory cytokines may be an aspect of HBO-mediated protection as it would reduce the cascade effects due to decreased ROS production and consequent reduction of oxidative stress at a distance.

Under the conditions of the experiment, increasing the pressure to 3 ATA increased the dissolved oxygen concentration in plasma independently of vascular circulation and hemoglobin saturation; this would theoretically produce an increase in the oxygen concentration in the ischemic tissue, benefiting cellular mechanisms during circulatory deficit. This higher concentration of dissolved oxygen in bodily fluids was assumed to be favorable to cellular metabolism and to have led to a lower inflammatory response, lower ROS generation and decreased expression of antioxidant genes due to the application of $\mathrm{HBO}$ in the ischemia phase. However, during reperfusion periods, HBO would induce a decrease in cytokine production, inhibition of neutrophil adhesion to the vascular endothelium and consequently lower oxidative stress in lung tissue with decreased antioxidant gene expression. In absolute numbers, our results are consistent with these theories, but with respect to statistical significance, the change in expression of the two hyperexpressed genes, Gpx4 and $L p o$, was significant only in the IRG and $\mathrm{HBO}+\mathrm{I}$ group.

\section{Conclusions}

In lung tissue, IIR promoted hyperexpression of the Gpx4 and Lpo genes, which are related to cellular defense against oxidative stress. This altered expression was considered to represent the need of the cell to produce more antioxidant defense proteins encoded by these genes due to the greater presence of ROS caused by IIR.

Treatment with HBO decreased the expression of the Gpx4 and Lpo genes, demonstrating a decreased need for the antioxidant response due to the reduced presence of ROS induced by $\mathrm{HBO}$ and suggesting that $\mathrm{HBO}$ has a beneficial effect on pulmonary oxidative stress when applied during ischemia.

\section{- References}

1. Gonzales LM, Moeser AJ, Blikslager AT. Animal models of ischemia reperfusioninduced intestinal injury: progress and promise for translational research. Am J Physiol Gastrointest Liver Physiol. 2015;308(2):63-75. doi: 10.1152/ ajpgi.00112.2013.

2. Granger DN, Kvietys PR. Reperfusion injury and reactive oxygen species: the evolution of a concept. Redox Biol. 2015;6:524-51. doi: 10.1016/j.redox.2015.08.020.

3. Bayomy NA, Elshafhey SH, ElBakary RH, Abdelaziz EZ. Protective effect of hesperidin against lung injury induced by intestinal ischemia/reperfusion in adult albino rats: histological, immunohistochemical and biochemical study. Epub. 2014;46(5):30410. doi: 10.1016/j.tice.2014.05.009.

4. Thom SR. Hyperbaric oxygen - its mechanisms and efficacy. Plast Reconstr Surg. 2012;127(1):131-41. doi: 10.1097/ PRS.0b013e3181fbe2bf.

5. Gill AL, Bell CNA. Hyperbaric oxygen: its uses, mechanisms of action and outcomes. QJM. 2004;97(7):385-95. doi: 10.1093/ qjmed/hch074.

6. Pfaffl MW. A new mathematical model for relative quantification in real-time RT-PCR. Nucleic Acids Res. 2001;29(9):2002-7. doi: 10.1093/nar/29.9.e45.

7. Ding C, Cantor CR. Quantitative analysis of nucleic acids - the last few years of progress. J Biochem Mol Biol. 2004;37(1):1-10. doi: 10.5483/BMBRep.2004.37.1.001.

8. Bertoletto PR, Ikejiri AT, SomaioNeto F, Chaves JC, Teruya R, Bertoletto ER, Taha $\mathrm{MO}$, Fagundes DJ. Oxidative stress gene expression profile in inbred mouse after ischemia/reperfusion small bowel injury. Acta Cir Bras. 2012;27(11):773-82. doi: 10.1590/S0102-86502012001100006.

9. Ikejiri AT, Somaio Neto F, Chaves JC, Bertoletto PR, Teruya R, BertolettoER,Taha 
MO, Fagundes DJ. Gene expression profile of oxidative stress in the lung of inbred mice after intestinal ischemia/reperfusion injury. Acta Cir Bras. 2014;29(3):186-92. doi: 10.1590/S0102-86502014000300007.

10.Teruya R, Ikejiri AT, Somaio Neto F, Chaves JC, Bertoletto PR, Taha MO, Fagundes DJ. Expression of oxidative stress and antioxidant defense genes in the kidney of inbred mice after intestinal ischemia and reperfusion. Acta Cir Bras. 2013;28(12):848-55. doi: $10.1590 / \mathrm{S} 0102-86502013001200007$.

11.Somaio Neto F, Ikejiri AT, Bertoletto PR, Chaves JC, Teruya R, Fagundes DJ. Hyperbaric oxygenation and the genic expression related to oxidative stress in the heart of mice during intestinal ischemia and reperfusion. Acta Cir Bras. 2017;32(11):913-23. doi: 10.1590/s0102-865020170110000003.

12.Andrade Júnior DR, Souza RB, Santos SA, Andrade $D R$. Os radicais livres de oxigênio e as doenças pulmonares. J Bras Pneumol. 2005;31(1):60-8. doi: 10.1590/S180637132005000100011.

13.Aquilano K, Baldelli S, Ciriolo MR. Glutathione: new roles in redox signaling for an old antioxidant. F Phar. 2014;196(5):112. doi: 10.3389/fphar.2014.00196.

14.Brigelius-Flohé $\mathrm{R}$, Matilde Maiorino $M$. Glutathione peroxidases. Biochim Biophys Acta. 2013;1830:3289-303. doi: 10.1016/j. bbagen.2012.11.020.

15.Ballatori N, Krance SM, Notenboom S, Shi S, Tieu K, Hammond CL. Glutathione dysregulation and the etiology and progressino of human diseases. Biol Chem. 2009;390:191-214. doi: 10.1515/BC. 2009.033.

16.Liang $\mathrm{H}$, Remmen HV, FrohlichV, Lechleiter J, Richardson A, Ran Q. Gpx4 protects mitochondrial ATP generation against oxidative damage. Biochem Biophys Res Commun. 2007;356:893-8. doi: 10.1016/j. bbrc.2007.03.045.

17. Maiorino M, Conrad M, Ursini F. GPx4, lipid peroxidation and cell death: discoveries, rediscoveries and open issues. Antioxid Redox Signal. 2017 May 30. doi: 10.1089/ ars.2017.7115.

18.Bafort F, Parisi O, Perraudin JP, Jijakli $\mathrm{MH}$. Mode of action of lactoperoxidase as related to its antimicrobial activity: a review. Enzyme Res. 2014;2014:1-13. doi:
$10.1155 / 2014 / 517164$.

19. Welk A, Rudolph P, Kreth J, Schwahn C, Kramer A, Below H. Microbicidal efficacy of thiocyanate hydrogen peroxide after adding lactoperoxidase under saliva loading in the quantitative suspension test. J Arch Oral Bio. 2011;56:1576-82. doi: 10.1016/j. archoralbio.2011.04.016.

20.Wijkstrom-Frei C, El-Chemaly S, Ali-Rachedi R, Gerson C, Cobas MA, Forteza R, Salathe $\mathrm{M}$, Conner GE. Lactoperoxidase and human airway host defense. Am J Respir Cell Mol Biol. 2003;29(2):206-12. doi: 10.1165/ rcmb.2002-01520C.

21.Gerson C, Sabater J, Scuri M, Torbati A, Coffey R, Abraham JW, Lauredo I, Forteza R, Wanner A, Salathe M, Abraham WM, Conner GE. The lactoperoxidase system functions in bacterial clearance of airways. Am J Respir Cell Mol Biol. 2000;22:665-71. doi: 10.1165/ajrcmb.22.6.3980.

22.El-Chemaly S, Salathe M, Baier S, Conner $\mathrm{GE}$, Forteza R. Hydrogen peroxidescavenging properties of normal human airway secretions. Am J Respir Crit Care Med. 2003;167:425-30. doi: 10.1164/ rccm.200206-5310C.

23.Conner GE, Salathe $M$, Forteza $R$. Lactoperoxidase and hydrogen peroxide metabolism in the airway. Am J Respir Crit Care Med. 2002;166:57-61. doi: 10.1164/ rccm.2206018.

24. Kinbara M, Ueda T, Hirai K. Expression of peroxidase activity in rat tracheal epithelial cells associated with mycoplasma pulmonis. Am J Physiol. 1992;262:92-9. doi: 10.1152/ ajplung.1992.262.1.L92.

25.Sisecioglu $M$, Gulcin I, Cankaya $M$, Atasever A, Ozdemir $H$. The inhibitory effects of I-adrenaline on lactoperoxidase enzyme purified from bovine milk. Int J Food Propersties. 2012;5(11):1351-6. doi: 10.1080/10942912.2010.511924.

26.Ambiru S, Furuyama N, Aono M, Otsuka H, Suzuki T, Miyazaki M. Analysis of risk factors associated with complications of hyperbaric oxygen therapy. J Crit Care. 2008;23(3):295300. doi: 10.1016/j.jcrc.2007.08.002.

27. Bennett MH, Lehm JP, Jepson N. Hyperbaric oxygen therapy for acute coronary syndrome. Cochrane Database Syst Rev. 2015;7:CD004818. doi: 10.1002/14651858. CD004818. 
28.Thom SR, Veena M, Bhopale VM, Milovanova TN, Yang $M$, Bogush $M$, Buerk DG. Nitric oxide synthase-2 linkage to focal adhesion kinase in neutrophils influences enzyme activity and B2 integrin function. JBC. 2013;288(7):4810-8. doi: 10.1074/jbc. M112.426353.

29.Buras JA, Reenstra WR. Endothelialneutrophil interactions during ischemia and reperfusion injury: basic mechanisms of hyperbaric oxygen. Neurol Res. 2007;29:12731. doi: 10.1179/016164107X174147.

30.Benson RM, Minter LM, Osborne BA, Granowitz EV. Hyperbaric oxygen inhibits stimulus-induced proinflammatory cytokine synthesis by human blood-derived monocyte-macrophages. Clin Exp Immunol. 2003;134(1):57-62. doi: 10.1046/j.13652249.2003.02248.x.

\section{Acknowledgements}

To Operative Technique and Experimental Surgery Division, Department of Surgery and Molecular Gynecology Facilities (UNIFESP); Marcos Azevedo Junior, biologist and Fellow PhD degree in the Molecular Gynecology Postgraduate Program at UNIFESP, for the gene expression technology and advisory support; Ismael Dale Cotrin Guerreiro da Silva, Associate Professor, Department of Gynecology and Head of Molecular Gynecology Facilities at UNIFESP, for support with the analysis of the gene expression data.

\section{Correspondence:}

Adauto Tsutomu Ikejiri

Rua João Vicente Ferreira, 1789

79824-030 Dourados - MS Brasil

Tel.: (55 67)3421-7171

adalto.ike@uol.com.br

Received: Jan 10, 2018

Review: Mar 12, 2018

Accepted: Apr 13, 2018

\section{Conflict of interest: none}

Financial source: none

${ }^{1}$ Research performed at Experimental Surgery Department, Medical School, Universidade Federal da Grande Dourados (UFGD); Operative Technique and Experimental Surgery Division, and Molecular Gynecology Facilities, Universidade Federal de São Paulo, Brazil. Part of PhD degree thesis, Postgraduate Program in Interdisciplinary Surgical Sciences, UNIFESP. Tutor: Djalma José Fagundes. 